\title{
Characteristics and outcomes of hospital admissions for COVID-19 and influenza in the
} Toronto area

\author{
Amol A. Verma MD MPhil, Tejasvi Hora BSc, Hae Young Jung MSc, Michael Fralick MD PhD, Sarah L. Malecki MD MSc, \\ Lauren Lapointe-Shaw MD PhD, Adina Weinerman MD MHSc, Terence Tang MD, Janice L. Kwan MD MPH, \\ Jessica J. Liu MD, Shail Rawal MD MPH, Timothy C.Y. Chan PhD LEL, Angela M. Cheung MD PhD, Laura C. Rosella PhD, \\ Marzyeh Ghassemi PhD, Margaret Herridge MD MSc, Muhammad Mamdani MPH PharmD, Fahad Razak MD MSc
}

Cite as: CMAJ 2021 March 22;193:E410-8. doi: 10.1503/cmaj.202795; early-released February 10, 2021

Visual abstract available at: https://www.cmaj.ca/lookup/doi/10.1503/cmaj.202795/tab-related-content

\section{ABSTRACT \\ BACKGROUND: Patient characteristics, clinical care, resource use and out- comes associated with admission to hospital for coronavirus disease 2019 (COVID-19) in Canada are not well described.}

METHODS: We described all adults with COVID-19 or influenza discharged from inpatient medical services and medical-surgical intensive care units (ICUs) between Nov. 1, 2019, and June 30, 2020, at 7 hospitals in Toronto and Mississauga, Ontario. We compared patient outcomes using multivariable regression models, controlling for patient sociodemographic factors and comorbidity level. We validated the accuracy of 7 externally developed risk scores to predict mortality among patients with COVID-19.

RESULTS: There were 1027 hospital admissions with COVID-19 (median age $65 \mathrm{yr}, 59.1 \%$ male) and 783 with influenza (median age $68 \mathrm{yr}, 50.8 \%$ male). Patients younger than 50 years accounted for $21.2 \%$ of all admissions for COVID-19 and $24.0 \%$ of ICU admissions. Compared with influenza, patients with COVID-19 had significantly greater in-hospital mortality (unadjusted $19.9 \%$ v. $6.1 \%$, adjusted relative risk [RR] 3.46, 95\% confidence interval [CI] 2.56-4.68), ICU use (unadjusted $26.4 \%$ v. $18.0 \%$, adjusted RR 1.50 , $95 \% \mathrm{Cl} 1.25-1.80$ ) and hospital length of stay (unadjusted median $8.7 \mathrm{~d}$ v. $4.8 \mathrm{~d}$, adjusted rate ratio $1.45,95 \% \mathrm{Cl} 1.25-$ 1.69). Thirty-day readmission was not significantly different (unadjusted 9.3\% v. $9.6 \%$, adjusted RR $0.98,95 \% \mathrm{Cl} 0.70-$ 1.39). Three points-based risk scores for predicting in-hospital mortality showed good discrimination (area under the receiver operating characteristic curve $[A \cup C]$ ranging from 0.72 to 0.81 ) and calibration.

INTERPRETATION: During the first wave of the pandemic, admission to hospital for COVID-19 was associated with significantly greater mortality, ICU use and hospital length of stay than influenza. Simple risk scores can predict inhospital mortality in patients with COVID-19 with good accuracy. nternational studies report that patients admitted to hospital with coronavirus disease 2019 (COVID-19) have high rates of critical illness and mortality. ${ }^{1-5}$ Two small Canadian case series have described care for critically ill patients with COVID-19 and found mortality rates of up to $25 \% .^{6,7}$ However, outcomes of patients admitted to hospital for COVID-19 in Canada are not well described, particularly outside of intensive care units (ICUs). Case fatality rates for COVID-19 vary dramatically worldwide, ${ }^{8}$ and outcomes of patients admitted to hospital for COVID-19 in Canada may differ from other countries because of differences in populations, public health and health care systems.

Seasonal influenza is a useful comparator for COVID-199-11 as it is another respiratory virus, familiar to the general public, with high rates of morbidity and mortality. The purpose of this study was to describe patient characteristics, resource use, clinical care and outcomes for patients admitted to hospital with COVID-19 in Ontario, Canada, using influenza as a comparator. We also validated the performance of various prognostic risk scores for in-hospital mortality among patients with COVID-19. 


\section{Methods}

\section{Design and setting}

We conducted this retrospective cohort study using data from 7 large hospitals (5 academic and 2 community-based teaching hospitals) in Toronto and Mississauga, Ontario, that participate in GEMINI, a hospital research collaborative. ${ }^{12}$

\section{Data collection}

We collected administrative and clinical data from hospital information systems for GEMINI, as previously described. ${ }^{12,13}$ We collected patient demographics, hospital resource use and outcomes from hospitals, as reported to the Canadian Institute for Health Information (CIHI) Discharge Abstract Database and the National Ambulatory Care Reporting System. We extracted additional clinical data, including laboratory test results, radiology tests, vital signs and inhospital medication orders from hospital information systems (see Appendix 1, available at www.cmaj.ca/lookup/doi/10.1503/ cmaj.202795/tab-related-content, for details regarding data quality).

\section{Study population}

We included all adults over 18 years admitted to an inpatient medical service or medical-surgical ICU, including coronary care units, and discharged between Nov. 1, 2019, and June 30, 2020. Medical services included all medical specialties (e.g., general medicine, cardiology, respirology). This captures all hospital admissions for COVID-19 and influenza and their medical complications, but may miss a small number of COVID-19 or influenza patients admitted for nonmedical reasons who were not subsequently transferred to a medical service.

We identified patients with COVID-19 based on the enhanced Canadian version of the International Classification of Diseases and Related Health Problems, 10th Revision (ICD-10-CA) codes, namely U07.1 ("COVID-19 diagnosis confirmed by a laboratory test") ${ }^{14}$ and U07.2 ("COVID-19 diagnosed clinically or epidemiologically but lab results inconclusive, unavailable, or not performed"). ${ }^{14}$ In 150 hospitals in the United States, the U07.1 code was $98 \%$ sensitive and $99 \%$ specific for COVID-19. ${ }^{15}$ We identified patients with influenza based on a validated ICD-10-CA algorithm (codes J09, J10.0, J10.1, J10.8, $\mathrm{J} 11.0, \mathrm{~J} 11.1$ and $\mathrm{J} 11.8$ ) that was $83 \%$ sensitive and $98 \%$ specific for influenza in Ontario. ${ }^{16}$ Fewer than 6 patients had coexisting COVID-19 and influenza (exact number suppressed to limit risk of patient reidentification), and these were included in the COVID-19 group.

\section{Outcomes and process measures}

The 5 main outcomes of interest were in-hospital mortality, unplanned readmission to any medical service or medicalsurgical ICU service at any participating hospital within 30 days of discharge, admission to the ICU, total hospital length of stay and ICU length of stay. We also report 7-day readmission and emergency department length of stay.

We describe use of thoracic computed tomography (CT), because of its role in diagnosis of COVID-19, ${ }^{17}$ and in-hospital use of antibiotics that are known to be used for respiratory infections (see Appendix 1), ${ }^{18-20}$ anticoagulants and systemic corticosteroids, as captured by medication orders after admission. Use of these medications may be associated with COVID-19, ${ }^{21,22}$ although our study period was before the publication of the RECOVERY trial's results regarding dexamethasone. ${ }^{21}$ We used codes from the Canadian Classification of Health Interventions, as reported to $\mathrm{ClHI}$, to identify the use of invasive mechanical ventilation, dialysis (including both newly initiated and chronic dialysis) and gastrointestinal endoscopy and bronchoscopy. Dialysis may be more commonly used in patients with COVID-19, ${ }^{23}$ and gastrointestinal endoscopy and bronchoscopy are common invasive procedures that have been a source of concern for COVID-19 transmission. ${ }^{24,25}$

\section{Patient characteristics}

We report patient age, sex, residence in a long-term care facility and transfer from an acute care hospital, as well as laboratory test results and vital signs at time of presentation. We categorized comorbid conditions based on ICD-10-CA codes using the Clinical Classification Software Refined ${ }^{26,27}$ and the Charlson Comorbidity Index. ${ }^{28}$ Although individual patient income and ethnicity were not available, we used postal codes to report neighbourhood-level income and proportion of the population who identify as a visible minority (see Appendix 1)..$^{29,30}$ Neighbourhoods were categorized into quintiles with Q1 to Q5 representing lowest to highest income and proportion of the population who identify as a visible minority, respectively.

\section{Mortality prediction scores}

We calculated in-hospital risk of mortality in patients with COVID19 and influenza using adaptations of 7 scores, based on demographic and clinical data available in the first 24 hours of admission. The modified Acute Physiology and Chronic Health Evaluation (mAPACHE) score ${ }^{31}$ and the critical illness severity scoring system (CISSS) ${ }^{32}$ were originally developed to predict ICU and 30-day mortality using routinely collected electronic clinical data. We also selected the 4 best-performing models $\left(\mathrm{Lu}^{33} \mathrm{Hu},{ }^{34}\right.$ $\mathrm{Xie}^{35}$ and NEWS2 ${ }^{36}$ ) in a United Kingdom-based external validation study ${ }^{37}$ of models identified in a living systematic review of prediction models for mortality from COVID-19. ${ }^{38}$ Finally, we included the ISARIC Coronavirus Clinical Characterisation Consortium 4C (ISARIC-4C) mortality score, ${ }^{39}$ which was derived in a large UK cohort (see Appendix 1 for details).

\section{Statistical analysis}

We compared baseline characteristics between patients with COVID-19 and influenza using standardized differences, with standardized differences $>0.1$ suggesting imbalance between groups. ${ }^{40}$ We compared unadjusted differences in clinical care, resource use and clinical outcomes using $\chi^{2}$ tests, Student $t$ tests, and MannWhitney tests for categorical, symmetrically distributed continuous and non-normal continuous variables, respectively. To account for multiple testing, we report Bonferroni-corrected $p$ values for all comparisons except the 5 main prespecified outcomes. We used multivariable regression to compare outcomes after adjusting for patient age, sex, Charlson score, residence in long-term care, neighbourhood income, neighbourhood proportion of the population who identify as a visible minority and admitting hospital. Covariates were selected a priori based on previously reported 
associations with mortality in COVID-19. ${ }^{10,41-43}$ Poisson regression ${ }^{44}$ was used for models of mortality, readmission and ICU admission to provide risk ratios and avoid misinterpretation of odds ratios obtained from logistic regression. Negative binomial regression was used for models of hospital length of stay and ICU length of stay. To report performance of risk scores for predicting in-hospital mortality in COVID-19, we calculated area under the receiver operating characteristic curve (AUC), as well as sensitivity, specificity, negative predictive value and positive predictive value at various thresholds. We report model calibration visually by plotting model scores versus observed outcome proportions for points-based systems, and Loess-smoothed calibration plots, comparing observed to predicted probabilities, for probability score-based systems.

\section{Subgroup and sensitivity analyses}

First, we examined outcomes stratified by age group, specified a priori as $<50$ years, $50-75$ years and $>75$ years. Second, we report patient characteristics and outcomes among the patients admitted to ICU. Third, to explore the question of whether patients died from, rather than with, COVID-19, we report the "most responsible" (primary) discharge diagnoses among patients admitted to hospital with COVID-19. Fourth, we replicated all analyses, excluding patients with no laboratory confirmation of a COVID-19 diagnosis based on code U07.2. Fifth, because participating hospitals are tertiary and quaternary care centres with large critical care units, we replicated analyses after including only patients admitted through the emergency department. This excluded interfacility transfers, which primarily involve patients transferred for critical care and might lead to an overestimation of illness severity. Sixth, to account for competing risks, we modelled ICU admission and death as a composite outcome. Finally, to account for patient-level clustering, we replicated our main analyses using a randomly selected single admission for patients with multiple admissions.

\section{Ethics approval}

Research ethics board approval was obtained from the University Health Network (Toronto), Sunnybrook Health Sciences Centre (Toronto) and St. Michael's Hospital (Toronto) through the integrated Clinical Trials Ontario platform, with St. Michael's Hospital as the "Board of Record." Research ethics board approval was also obtained from Trillium Health Partners (Mississauga) and Mount Sinai Hospital (Toronto).

\section{Results}

The cohort included 783 admissions to hospital with influenza in 763 unique patients and 1027 admissions with COVID-19 (including 944 laboratory-confirmed diagnoses) in 972 unique patients. These represented $23.5 \%$ of all Ontario hospital admissions for COVID-19 $(n=4373)^{45}$ during the study period.

\section{Patient characteristics}

Patients with COVID-19 and influenza had a median age of 65 years (interquartile range [IQR] 53-79) and 68 years (IQR 55-80), respectively (Table 1 ). Patients with COVID-19 were more likely to be male (59.1\% v. $50.8 \%$ ), have a Charlson score
Table 1: Characteristics of admissions to hospital for COVID-19 and influenza

\begin{tabular}{|c|c|c|c|}
\hline \multirow[b]{2}{*}{ Variable } & \multicolumn{2}{|c|}{ No. (\%) of admissions ${ }^{\star}$} & \multirow[b]{2}{*}{ SD† } \\
\hline & $\begin{array}{c}\text { COVID-19 } \\
n=1027\end{array}$ & $\begin{array}{c}\text { Influenza } \\
n=783\end{array}$ & \\
\hline Unique patients & $972(94.6)$ & $763(97.4)$ & $\mathrm{N} / \mathrm{A}$ \\
\hline Age, yr, median (IQR) & $65(53-79)$ & $68(55-80)$ & 0.07 \\
\hline Age group, yr & & & 0.09 \\
\hline$<50$ & $218(21.2)$ & $141(18.0)$ & \\
\hline $50-75$ & $480(46.7)$ & $390(49.8)$ & \\
\hline$>75$ & $329(32.0)$ & $252(32.2)$ & \\
\hline Sex, male & $607(59.1)$ & $398(50.8)$ & 0.17 \\
\hline Charlson score & & & 0.31 \\
\hline 0 & $556(54.1)$ & $304(38.8)$ & \\
\hline 1 & $183(17.8)$ & $175(22.3)$ & \\
\hline$\geq 2$ & $288(28.0)$ & $304(38.8)$ & \\
\hline
\end{tabular}

Neighbourhood income quintile

$\begin{array}{lcc}1 \text { (lowest) } & 351(34.2) & 248(31.7) \\ 2 & 177(17.2) & 139(17.8) \\ 3 & 153(14.9) & 127(16.2) \\ 4 & 163(15.9) & 142(18.1) \\ 5 \text { (highest) } & 112(10.9) & 95(12.1) \\ \text { Missing } & 71(6.9) & 32(4.1)\end{array}$

Neighbourhood visible minority quintile

1 (lowest)
2
3
4
5 (highest)
Missing

$\begin{array}{cc}100(9.7) & 100(12.8) \\ 196(19.1) & 167(21.3) \\ 264(25.7) & 171(21.8) \\ 181(17.6) & 166(21.2) \\ 212(20.6) & 138(17.6) \\ 74(7.2) & 41(5.2) \\ 120(11.7) & 35(4.5) \\ 90(8.8) & 24(3.1)\end{array}$

Long-term care resident

Transfer from acute care hospital

Comorbidities $\ddagger$

Hypertension
Diabetes mellitus
Renal failure
Neurocognitive disorders
Coronary heart disease
Heart failure
COPD

$\begin{array}{ccc}356(34.7) & 252(32.2) & 0.05 \\ 284(27.7) & 229(29.2) & 0.04 \\ 212(20.6) & 169(21.6) & 0.02 \\ 174(16.9) & 105(13.4) & 0.10 \\ 63(6.1) & 63(8.0) & 0.08 \\ 62(6.0) & 98(12.5) & 0.23 \\ 55(5.4) & 96(12.3) & 0.25\end{array}$

Note: $\mathrm{COPD}=$ chronic obstructive pulmonary disease, COVID-19 = coronavirus disease $2019, \mathrm{IQR}=$ interquartile range, $\mathrm{N} / \mathrm{A}=$ not applicable, $\mathrm{SD}=$ standardized difference. *Unless indicated otherwise.

$\dagger S D>0.1$ reflects imbalance between groups. ${ }^{40}$

$\ddagger$ Comorbidities were categorized from ICD-10-CA discharge diagnoses using the Clinical Classification Software Refined tool. ${ }^{26}$ 
of $0(54.1 \%$ v. $38.8 \%)$, and reside in long-term care $(11.7 \% \mathrm{v}$. $4.5 \%)$. Patients living in neighbourhoods with lower income appeared to be overrepresented in both COVID-19 (Q1 34.2\% v. Q5 10.9\%) and influenza (Q1 31.7\% v. Q5 12.1\%) groups, whereas there was no clear gradient for the proportion who identify as a visible minority. Hypertension and diabetes mellitus were common comorbidities among both COVID-19 and influenza groups, whereas chronic obstructive pulmonary disease and heart failure were more common in the influenza group than the COVID-19 group (Table 1 ).

Presenting vital signs did not differ meaningfully between the COVID-19 and influenza groups. Supplemental oxygen was used within the first 72 hours for $44.9 \%$ of patients admitted to hospital with COVID-19 and $37.7 \%$ of patients admitted with influenza. Patients with COVID-19 had somewhat higher inflammatory markers than patients with influenza (e.g., C-reactive protein, dimerized plasmin fragment D [D-dimer], ferritin, lactate dehydrogenase); tests for these markers were also ordered more commonly for patients with COVID-19 (Table 2).

\section{Mortality and readmission}

Patients with COVID-19 had significantly greater unadjusted and adjusted in-hospital deaths than patients with influenza (unadjusted $19.9 \%$ v. $6.1 \%, p<0.001$, adjusted relative risk [RR] 3.46, 95\% confidence interval [CI] 2.56-4.68) (Table 3, Table 4). Readmission within 7 days and 30 days occurred in $4.3 \%$ and $9.3 \%$ of patients with COVID-19, respectively, which was not significantly different from patients with influenza, before or after adjustment.

Among patients admitted to hospital with COVID-19, the most responsible discharge diagnosis was COVID-19, viral pneumonia, sepsis or palliative care in $183(89.7 \%)$ of the 204 patients who died and in $681(82.7 \%)$ of the 823 patients who were alive at discharge.

\section{Hospital resource use and clinical care}

Compared with patients with influenza, patients with COVID-19 had greater ICU use (unadjusted 26.4\% v. 18.0\%, $p<0.001$; adjusted RR $1.50,95 \% \mathrm{Cl} 1.25-1.80$ ) and hospital length of stay (unadjusted median 8.7 d v. $4.8 \mathrm{~d}, p<0.001$; adjusted rate ratio $1.45,95 \% \mathrm{Cl} 1.25-1.69$ ) (Table 3, Table 4), but ICU length of stay was not significantly different after adjustment (Table 3, Table 4 and Appendix 1, Table S2).

Patients with COVID-19 were more likely to receive invasive mechanical ventilation $(18.5 \%$ v. $9.3 \%, p<0.001)$ but less likely to receive bronchoscopy $(2.0 \%$ v. $5.6 \%, p=0.005)$. Patients with COVID-19 received at least 1 thoracic CT in 20.4\% of cases and systemic corticosteroids were ordered in $16.7 \%$ of cases.

\section{Age-stratified outcomes}

Among patients with COVID-19 who were younger than 50 years, 50-75 years and older than 75 years of age, unadjusted mortality was $5.1 \%, 13.5 \%$ and $38.9 \%$, respectively. Intensive care unit use among each age group was $29.8 \%, 35.2 \%$ and $11.3 \%$, respectively, and 30 -day readmission was $9.2 \%, 9.9 \%$ and $7.9 \%$, respectively (Appendix 1, Table S1).

\section{Mortality prediction scores}

Discrimination and calibration of prognostic scores are reported in Table 5 and Appendix 1 (Table S3, Table S4 and Figure S1). Complete data were available for between $1 \%$ (ISARIC-4C) and $46 \%$ (Xie) of cases. Discriminative accuracy was best for mAPACHE (AUC 0.86 for cases with complete data and 0.81 after imputation), CISSS (AUC 0.83 for cases with complete data and 0.80 after imputation) and ISARIC-4C (AUC 0.78 after imputation). Model calibration was poor for the regression-based models ( $\mathrm{Hu}$, Xie and CISSS), whereas observed risk increased in a roughly linear manner for the points-based scores (Appendix 1, Figure S1).

Overall findings were generally unchanged in all sensitivity analyses (see Appendix 1 for details).

\section{Interpretation}

Our study contributes to comparisons of COVID-19 with seasonal influenza. The infection fatality rate of COVID-19 may be as much as 10 times greater than influenza, ${ }^{46,47}$ but these comparisons are indirect and have been disputed. ${ }^{48}$ We found patients with COVID-19 had a greater risk of death (3.5 times) and ICU admission (1.5 times), and longer hospital stays (1.5 times) than patients with influenza, which is similar to differences recently reported in France $^{10}$ and the US. ${ }^{11}$ Thus, hospital admissions for COVID-19 are substantially more severe than seasonal influenza. These differences may be magnified by low levels of immunity to the novel coronavirus compared with seasonal influenza, for which patients may have some immunity from past infections and vaccination. The relative severity may change as immunity to severe acute respiratory syndome coronavirus 2 (SARS-CoV-2) increases and effective therapies are developed.

Hospital admissions for COVID-19 in Canada have not been well described. Among patients admitted to the ICU for COVID19 , we found that about two-thirds of patients received invasive mechanical ventilation and one-quarter died, which is similar to the results of 2 small Canadian ICU studies. ${ }^{6,7}$ We extend this literature by including patients who did not require admission to the ICU, finding that about one-quarter of all patients admitted to hospital for COVID-19, and one-fifth of those admitted through the emergency department, used the ICU. In the global context, patients with COVID-19 in Ontario (median age $65 \mathrm{yr}$ ) were somewhat older than patients in China (median 51-56 yr) 5,46 $^{5}$ and the US (median 62-63 yr), ${ }^{1-3}$ and were younger than those in the UK (median $73 \mathrm{yr}$ ), ${ }^{4}$ but mortality and ICU use were generally similar. We found that nearly 1 in 10 patients with COVID-19 were readmitted within 30 days, which is consistent with reports from the US. 3,50

Compared with patients with influenza, patients with COVID19 were more likely to be male and reside in long-term care, which is consistent with evidence that COVID-19 affects men more severely ${ }^{51}$ and has burdened long-term care facilities in Ontario. ${ }^{43,52}$ Patients from neighbourhoods with lower income were overrepresented in both the COVID-19 and influenza groups, reminding us that the socioeconomic gradients in COVID- $19^{53}$ are emblematic of those that exist for many diseases, including influenza. ${ }^{54}$ Notably, a majority of patients admitted to 
Table 2: Presenting vital signs, laboratory values and mortality risk scores in patients with COVID-19 and influenza*

COVID-19

\begin{tabular}{|c|c|c|c|c|c|c|}
\hline Variable & $\begin{array}{l}\text { Median (IQR) } \\
\text { result† }\end{array}$ & $\begin{array}{c}\text { No. }(\%) \\
\text { performed } \\
n=1027\end{array}$ & $\begin{array}{l}\text { Median (IQR) } \\
\text { result† }\end{array}$ & $\begin{array}{c}\text { No. }(\%) \\
\text { performed } \\
n=783\end{array}$ & SD of results $\ddagger$ & $\begin{array}{l}\text { SD of no. } \\
\text { performed } \ddagger\end{array}$ \\
\hline Temperature, degrees Celsius & $36.9(36.6-37.5)$ & $1000(97.4)$ & $36.9(36.6-37.4)$ & $578(73.8)$ & 0.07 & 0.71 \\
\hline Systolic BP, mm Hg & $126(114-142)$ & 1019 (99.2) & $129(114-148)$ & $568(72.5)$ & 0.03 & 0.83 \\
\hline Diastolic BP, mm Hg & $72(64-82)$ & 1019 (99.2) & $73(65-82)$ & $568(72.5)$ & $<0.01$ & 0.83 \\
\hline Heart rate, beats per min & $88(76-100)$ & 1019 (99.2) & 87 (75-99) & $568(72.5)$ & 0.05 & 0.83 \\
\hline Respiratory rate, breaths per min & $20(18-22)$ & $1017(99.0)$ & $18(18-20)$ & $564(72.0)$ & 0.18 & 0.83 \\
\hline $\mathrm{S} / \mathrm{F}$ ratio & $448(328-462)$ & $1007(98.1)$ & $452(438-467)$ & $551(70.4)$ & 0.40 & 0.82 \\
\hline Supplemental $\mathrm{O}_{2}$, no. $(\%) \S$ & $458(44.9)$ & 1019 (99.2) & $212(37.7)$ & $563(71.9)$ & 0.15 & 0.84 \\
\hline Hemoglobin, g/L & $127(111-141)$ & $1006(98.0)$ & $123(107-138)$ & $773(98.7)$ & 0.10 & 0.06 \\
\hline Hematocrit, L/L & $0.38(0.34-0.42)$ & 1005 (98.9) & $0.38(0.33-0.42)$ & $773(98.7)$ & 0.06 & 0.07 \\
\hline White blood cell count, $\times 10^{9} / \mathrm{L}$ & $7.6(5.5-10.6)$ & $1005(97.9)$ & $7.8(5.5-10.90)$ & $773(98.7)$ & $<0.01$ & 0.07 \\
\hline Platelets, $\times 10^{9} / \mathrm{L}$ & $214(164-281)$ & $1002(97.6)$ & $186(144-242)$ & $771(98.7)$ & 0.34 & 0.07 \\
\hline Neutrophils, $\times 10^{9} / \mathrm{L}$ & $5.6(3.8-8.3)$ & $1002(97.6)$ & $5.7(3.9-8.6)$ & $771(98.7)$ & $<0.01$ & 0.07 \\
\hline Lymphocytes, $\times 10^{9} / \mathrm{L}$ & $1.0(0.7-1.5)$ & $1000(97.4)$ & $0.9(0.5-1.3)$ & $771(98.7)$ & 0.10 & 0.08 \\
\hline Sodium, $\mathrm{mmol} / \mathrm{L}$ & $137(133-140)$ & $1002(97.6)$ & $136(133-139)$ & $775(99.0)$ & 0.18 & 0.11 \\
\hline Bicarbonate, $\mathrm{mmol} / \mathrm{L}$ & $25(22-27)$ & $939(91.4)$ & $25(22-27)$ & $763(97.4)$ & 0.01 & 0.27 \\
\hline Creatinine, $\mu \mathrm{mol} / \mathrm{L}$ & $89(70-124)$ & $998(97.2)$ & $96(72-135)$ & 770 (98.3) & 0.07 & 0.08 \\
\hline Urea, $\mathrm{mmol} / \mathrm{L}$ & $6.6(4.4-11.7)$ & $417(40.6)$ & $7.1(4.6-10.6)$ & $343(43.8)$ & 0.08 & 0.07 \\
\hline Albumin, g/L & $32(27-37)$ & $570(55.5)$ & $33(29-37)$ & $448(57.2)$ & 0.15 & 0.04 \\
\hline Bilirubin, $\mu \mathrm{mol} / \mathrm{L}$ & $9(7-13)$ & $850(82.8)$ & $9(6-14)$ & $599(76.5)$ & 0.01 & 0.16 \\
\hline C-reactive protein, $\mathrm{mg} / \mathrm{L}$ & $77(30-142)$ & $439(42.7)$ & $47(18-100)$ & $59(7.5)$ & 0.31 & 0.89 \\
\hline Lactate, $\mathrm{mmol} / \mathrm{L}$ & $1.7(1.3-2.4)$ & $758(73.8)$ & $1.7(1.3-2.5)$ & $605(77.3)$ & 0.05 & 0.09 \\
\hline $\mathrm{LDH}, \mathrm{U} / \mathrm{L}$ & $315(222-425)$ & $548(53.4)$ & $247(194-364)$ & $152(19.4)$ & 0.03 & 0.75 \\
\hline D-dimer, $\mu \mathrm{g} / \mathrm{L}$ FEU & $1030(672-1935)$ & $436(42.5)$ & $911(433-1780)$ & $41(5.2)$ & 0.09 & 0.97 \\
\hline Ferritin, $\mu \mathrm{g} / \mathrm{L}$ & $463(210-1124)$ & $390(38.0)$ & $316(120-675)$ & $84(10.7)$ & 0.12 & 0.67 \\
\hline Glucose, $\mathrm{mmol} / \mathrm{L}$ & $6.7(5.8-8.8)$ & $921(89.7)$ & $6.8(5.70-8.7)$ & $727(92.8)$ & 0.01 & 0.11 \\
\hline Arterial $\mathrm{PCO}_{2}, \mathrm{~mm} \mathrm{Hg}$ & $43(36-54)$ & $211(20.5)$ & $42(34-49)$ & $116(14.8)$ & 0.21 & 0.15 \\
\hline Arterial $\mathrm{PO}_{2}, \mathrm{~mm} \mathrm{Hg}$ & $73(62-94)$ & $211(20.5)$ & $81(66-126)$ & $116(14.8)$ & 0.36 & 0.15 \\
\hline Venous $\mathrm{PCO}_{2}, \mathrm{~mm} \mathrm{Hg}$ & $43(38-48)$ & $559(54.4)$ & $44(38-50)$ & $449(57.3)$ & 0.13 & 0.06 \\
\hline \multicolumn{7}{|l|}{ Mortality risk score } \\
\hline MAPACHE & $27(19-34)$ & $\mathrm{N} / \mathrm{A}$ & $28(21-35)$ & N/A & 0.14 & $\mathrm{~N} / \mathrm{A}$ \\
\hline CISSS & $0.03(0.01-0.06)$ & N/A & $0.03(0.02-0.06)$ & N/A & 0.05 & $\mathrm{~N} / \mathrm{A}$ \\
\hline Lu, category 3, no. (\%) & $581(57)$ & N/A & $515(66)$ & N/A & 0.19 & N/A \\
\hline $\mathrm{Hu}$ & $0.27(0.08-0.55)$ & $\mathrm{N} / \mathrm{A}$ & $0.27(0.10-0.51)$ & $\mathrm{N} / \mathrm{A}$ & 0.05 & $\mathrm{~N} / \mathrm{A}$ \\
\hline Xie & $0.14(0.06-0.26)$ & N/A & $0.16(0.07-0.27)$ & N/A & 0.04 & $\mathrm{~N} / \mathrm{A}$ \\
\hline ISARIC-4C & $9(7-11)$ & N/A & $9(8-11)$ & N/A & 0.08 & N/A \\
\hline NEWS2 & $5(2-9)$ & N/A & $4(1-6)$ & N/A & 0.52 & $\mathrm{~N} / \mathrm{A}$ \\
\hline
\end{tabular}

Note: $\mathrm{BP}=$ blood pressure, $\mathrm{CISS}=$ critical illness severity scoring system, COVID-19= coronavirus disease 2019, FEU = fibrinogen equivalent units (values standardized to this unit across sites if measurement units differed), ISARIC-4C = ISARIC Coronavirus Clinical Characterisation Consortium 4C, IQR = interquartile range, LDH = lactate dehydrogenase, mAPACHE = modified Acute Physiology and Chronic Health Evaluation, N/A = not applicable, NEWS2 $=$ National Early Warning Score, SD $=$ standardized difference, $S /$ F ratio $=$ ratio of oxygen saturation to fraction of inspired oxygen.

*We report the first valid laboratory test result and vital sign measurement collected between emergency department (ED) triage and $72 \mathrm{~h}$ after admission. Vital signs are not consistently recorded electronically at all hospitals, particularly when patients are in the ED or an intensive care unit. For patients with COVID-19 but not for those with influenza, vital signs were manually abstracted from medical records for the time period between ED triage and $24 \mathrm{~h}$ after admission (to calculate mortality risk scores). Mortality risk scores si-36,39 $^{31}$ were calculated based on first valid measurement between ED triage and $24 \mathrm{~h}$ after admission, and mean-imputed values when missing (Appendix 1 ). The possible point ranges for point-based scores were as follows: $\mathrm{mAPACHE}(0-159)$, Lu (1-3), ISARIC-4C (0-21), NEWS2 (0-20). The remaining scores are probability based (scores ranging from 0-1). Risk scores presented in this table were calculated based on mean imputation of missing laboratory data. The ISARIC-4C and NEWS2 scores were calculated only for cases with data available regarding mental status ( $n=242$ admissions with COVID-19 and $n=46$ with influenza). tUnless indicated otherwise.

$\ddagger S D>0.1$ reflects imbalance between groups.

$\S$ Supplemental $\mathrm{O}_{2}$ is the number of patients who required any amount of supplemental oxygen or mechanical ventilation. 


\begin{tabular}{|c|c|c|c|}
\hline \multirow[b]{2}{*}{ Variable } & \multicolumn{2}{|c|}{ No. (\%) of admissionst } & \multirow[b]{2}{*}{$p$ value } \\
\hline & $\begin{array}{l}\text { COVID-19 } \\
n=1027\end{array}$ & $\begin{array}{c}\text { Influenza } \\
n=783\end{array}$ & \\
\hline Death & $204(19.9)$ & $48(6.1)$ & $<0.001$ \\
\hline 7-day readmission $\ddagger$ & $32(4.3)$ & $22(3.1)$ & 1.09 \\
\hline 30-day readmission§ & $58(9.3)$ & $69(9.6)$ & 0.9 \\
\hline ICU use & $271(26.4)$ & $141(18.0)$ & $<0.001$ \\
\hline Hospital length-of-stay, d, median (IQR) & $8.7(3.6-18.9)$ & $4.8(2.3-10.4)$ & $<0.001$ \\
\hline ICU length-of-stay, d, median (IQR) & $10.9(4.0-17.8)$ & $6.0(2.3-13.0)$ & $<0.001$ \\
\hline ED length-of-stay, h, median (IQR) & $8.7(6.1-13.2)$ & $21.1(12.0-32.2)$ & $<0.001$ 甲 \\
\hline Invasive mechanical ventilation & $190(18.5)$ & $73(9.3)$ & $<0.0019$ \\
\hline Gastrointestinal endoscopy & $21(2.0)$ & $27(3.4)$ & 1.09 \\
\hline Bronchoscopy & $21(2.0)$ & $44(5.6)$ & 0.0059 \\
\hline Dialysis ${ }^{\star \star}$ & $79(7.7)$ & $43(5.5)$ & 1.09 \\
\hline Thoracic CT & $210(20.4)$ & $168(21.5)$ & 1.09 \\
\hline Respiratory antibiotic †† & $730(71.6)$ & $599(77.1)$ & 0.69 \\
\hline Corticosteroid & $170(16.7)$ & $284(36.6)$ & $<0.001$ 甲 \\
\hline Warfarin or DOAC & $157(15.4)$ & $156(20.1)$ & 0.69 \\
\hline $\begin{array}{l}\text { Note: COVID-19 = coronavirus disease } 2019, C T=c c \\
\text { department, ICU = intensive care unit, IQR = interq } \\
\text { *Readmission to medical service or medical-surgi } \\
\text { alive and for visits that could be linked to each oth } \\
\text { the number of patients receiving at least one of th } \\
\text { tUnless indicated otherwise. } \\
\text { tAfter excluding patients who died and those discl } \\
\text { COVID-19, } 720 \text { for influenza. } \\
\text { Affter excluding patients who died and those discl } \\
\text { COVID-19, } 718 \text { for influenza. } \\
\text { Ip values were adjusted using Bonferroni correcti } \\
\star \star \text { Dialysis included hemodialysis and peritoneal } \\
\text { † Respiratory antibiotics include all those listed in }\end{array}$ & $\begin{array}{l}\text { mography, DOAC }= \\
\text { ge. } \\
\text { e care unit at any pa } \\
\text { alid health insurance } \\
\text { cribed. } \\
\text { ee last } 7 \text { days of the } \\
\text { he last } 30 \text { days of the } \\
0 \text { secondary outcom } \\
\text { included both chro } \\
1 .\end{array}$ & $\begin{array}{l}\text { ral anticoagulant, ED } \\
\text { pital is reported amo } \\
\text { lospital resources and } \\
\text { ne denominator was } 7 \\
\text { the denominator was } \\
\text { N starts. }\end{array}$ & $\begin{array}{l}\text { sy } \\
\text { are, we report } \\
\text { sions for } \\
\text { ssions for }\end{array}$ \\
\hline
\end{tabular}

Table 4: Clinical outcomes in patients with COVID-19 compared with patients with influenza before and after multivariable adjustment*

\begin{tabular}{lcc} 
Outcome & $\begin{array}{c}\text { Unadjusted effect } \dagger \\
(\mathbf{9 5 \%} \mathbf{C I})\end{array}$ & $\begin{array}{c}\text { Adjusted effect } \dagger \\
(\mathbf{9 5 \%} \mathrm{CI})\end{array}$ \\
\hline Death & $3.24(2.40-4.38)$ & $3.46(2.56-4.68)$ \\
\hline ICU use & $1.47(1.22-1.76)$ & $1.50(1.25-1.80)$ \\
\hline 30-day readmission & $0.97(0.69-1.35)$ & $0.98(0.70-1.39)$ \\
\hline Hospital length-of-stay & $1.31(1.09-1.58)$ & $1.45(1.25-1.69)$ \\
\hline ICU length-of-stay & $0.93(0.57-1.52)$ & $1.25(0.92-1.70)$
\end{tabular}

Note: $\mathrm{Cl}=$ confidence interval, COVID-19 = coronavirus disease 2019, ICU = intensive care unit.

*Models were adjusted for patient age, sex, long-term care residence, Charlson comorbidity index score, admitting hospital, neighbourhood income quintile and neighbourhood quintile of proportion of the population who identify as a visible minority. Outcomes reported are: in-hospital death, admission to ICU at any point during hospitalization, readmission to a medical service or medical-surgical ICU at any participating hospital within 30 days of discharge, hospital length-of-stay and ICU length-of-stay.

†Poisson regression models were fit for death, ICU, and readmission (effect = relative risk) and negative binomial regression models were fit for hospital and ICU length-of-stay (effect = rate ratio). hospital with COVID-19 had low comorbidity (Charlson score zero) and one-fifth were younger than 50 years of age. Intensive care unit use was common in this younger age group, reinforcing that COVID-19 can cause serious illness in younger people and those with relatively little comorbid disease.

Mortality prediction in COVID-19 may inform clinical decision-making and resource allocation. Numerous prediction scores have been reported, ${ }^{38}$ but many were developed in small cohorts and require external validation. We found that mAPACHE had the best discriminative accuracy and good calibration. It also has the advantage of being designed for automated calculation in electronic medical records. ISARIC-4C and NEWS2 can both be easily calculated by bedside clinicians and have reasonably good discrimination and calibration. Performance of the NEWS2, Hu, Lu, and Xie models in our cohort was comparable to a single-centre validation study of 411 patients in the $\mathrm{UK},{ }^{37}$ and performance of ISARIC-4C was similar to its original description, ${ }^{39}$ strengthening confidence in these estimates of model performance. However, few admissions had complete data, mainly due to laboratory tests not being performed. For example, the ISARIC-4C score includes urea test results, which 
Table 5: Discriminative performance of mortality prediction scores in patients with COVID-19*

\begin{tabular}{|c|c|c|c|c|c|c|}
\hline Score & $\begin{array}{l}\text { Calculation } \\
\text { method }\end{array}$ & Predictors & $\begin{array}{c}\text { No. }(\%) \text { of } \\
\text { admissions with } \\
\text { complete data } \\
n=1027\end{array}$ & $\begin{array}{l}\text { AUC complete } \\
\text { data } \\
(95 \% \mathrm{CI})\end{array}$ & $\begin{array}{c}\text { No. }(\%) \text { of } \\
\text { admissions } \\
\text { after imputation } \\
n=1027\end{array}$ & $\begin{array}{l}\text { AUC after } \\
\text { imputation } \\
(95 \% \mathrm{Cl})\end{array}$ \\
\hline Lu & $\begin{array}{l}\text { Points-based } \\
\text { system }\end{array}$ & Age, CRP & 390 (37.9) & $0.71(0.66-0.76)$ & $1027(100)$ & $0.68(0.65-0.71)$ \\
\hline $\mathrm{Hu}$ & $\begin{array}{l}\text { Regression- } \\
\text { based system }\end{array}$ & Age, CRP, D-dimer, lymphocytes & $230(22.4)$ & $0.78(0.70-0.86)$ & $1027(100)$ & $0.72(0.68-0.76)$ \\
\hline Xie & $\begin{array}{l}\text { Regression- } \\
\text { based system }\end{array}$ & $\begin{array}{l}\text { Age, LDH, lymphocyte, oxygen } \\
\text { saturation }\end{array}$ & $469(45.6)$ & $0.80(0.75-0.85)$ & $972(94.6)$ & $0.75(0.71-0.79)$ \\
\hline ISARIC-4C & $\begin{array}{l}\text { Points-based } \\
\text { system }\end{array}$ & $\begin{array}{l}\text { Age, sex, Charlson comorbidities, } \\
\text { respiratory rate, oxygen saturation, } \\
\text { GCS score, urea, CRP }\end{array}$ & $12(1.2)$ & N/A $†$ & $242(23.6)$ & $0.78(0.70-0.85)$ \\
\hline MAPACHE & $\begin{array}{l}\text { Points-based } \\
\text { system }\end{array}$ & $\begin{array}{l}\text { Age, mechanical ventilation, } \\
\text { hematocrit, WBC, sodium, glucose, } \\
\text { bilirubin, urea, creatinine, } \\
\text { temperature, heart rate, respiratory } \\
\text { rate, mean arterial blood pressure, } \\
\text { metastatic cancer, AIDS, hepatic } \\
\text { failure, cirrhosis, leukemia, } \\
\text { lymphoma, immunosuppression, } \\
\text { multiple myeloma }\end{array}$ & $348(33.9)$ & $0.86(0.83-0.90)$ & $976(95.0)$ & $0.81(0.78-0.85)$ \\
\hline CISSS & $\begin{array}{l}\text { Regression- } \\
\text { based system }\end{array}$ & $\begin{array}{l}\text { Age, mechanical ventilation, } \\
\text { surgery, hematocrit, WBC, sodium, } \\
\text { glucose, bilirubin, creatinine, } \\
\text { bicarbonate, albumin, } \\
\text { temperature, heart rate, respiratory } \\
\text { rate, mean arterial blood pressure, } \\
\text { metastatic cancer, AIDS, hepatic } \\
\text { failure, cirrhosis, leukemia, } \\
\text { lymphoma, immunosuppression, } \\
\text { multiple myeloma }\end{array}$ & 357 (34.8) & $0.83(0.78-0.88)$ & $976(95.0)$ & $0.80(0.77-0.84)$ \\
\hline NEWS2 & $\begin{array}{l}\text { Points-based } \\
\text { system }\end{array}$ & $\begin{array}{l}\text { Respiratory rate, oxygen } \\
\text { saturation, systolic blood pressure, } \\
\text { heart rate, level of consciousness/ } \\
\text { new confusion, temperature }\end{array}$ & $242(23.6)$ & $0.72(0.63-0.80)$ & $242(23.6)$ & $0.72(0.63-0.80)$ \\
\hline
\end{tabular}

Note: $\mathrm{AUC}=$ area under the receiver operating characteristic curve, $\mathrm{Cl}=$ confidence interval, $\mathrm{CISS}=$ critical illness severity scoring system, $\mathrm{COVID}-19=$ coronavirus disease 2019 , CRP = C-reactive protein, GCS = Glasgow Coma Scale, ISARIC-4C = ISARIC Coronavirus Clinical Characterisation Consortium 4C, mAPACHE = modified Acute Physiology and Chronic Health Evaluation, $\mathrm{N} / \mathrm{A}=$ not applicable, NEWS2 $=$ National Early Warning Score, $\mathrm{WBC}=$ white blood cell count

${ }^{*}$ Mortality risk scores ${ }^{31-36,39}$ were calculated based on first valid measurement between emergency department triage and 24 hours after admission. We report model performance based on hospitalizations with complete data for all inputs and after mean imputation of missing laboratory test results (see Appendix 1 for details). We did not impute missing vital signs or mental/neurologic status data because we did not think it was reasonable to assume these values would be normal. The mortality rate in the $242 \mathrm{hospitalizations} \mathrm{on} \mathrm{which}$ ISARIC-4C and NEWS2 scores were validated was $17.4 \%$ (42 deaths).

tInsufficient sample to calculate.

was ordered in fewer than $11 \%$ of COVID-19 patients at 4 hospitals because previous resource stewardship initiatives curbed its use. Thus, calculating some scores may require changes to routine clinical practice, although model performance remained reasonable with simple mean imputation for missing values. Inconsistent capture of mental status (missing in $70 \%$ of admissions) limited the number of admissions to hospital in which we could validate NEWS2 and ISARIC-4C, but would not hinder the use of these scores in clinical practice. Our study provides strong external validation that death from COVID-19 can be predicted reasonably well with simple scores. Developing prediction models for the Canadian context, perhaps by adapting these externally developed scores, is an important area for future research.

\section{Limitations}

Our study has several limitations. First, we included 7 large academic hospitals that accepted COVID-19 transfers for critical care. To ensure we did not overestimate the severity of COVID-19, we replicated our analyses in patients admitted through the emergency department to exclude interfacility transfers, and findings were consistent. We believe our results are generalizable, as mortality in our cohort was similar to that reported in large studies from the US ${ }^{1}$ and UK, ${ }^{4}$ and we included about $25 \%$ of all patients admitted to hospital with COVID19 in Ontario. Second, we could collect only data that were captured systematically in administrative or electronic medical record sources, and thus could not report or adjust for patient preferences regarding critical care, presenting symptoms or some important risk factors, such as obesity and smoking. Our analyses of income and visible 
minority status could be performed only at the neighbourhood level, and thus are insufficiently granular to draw strong conclusions. Third, we report 30-day readmission at any participating hospital. Although this likely underestimates readmission, $82 \%$ of readmissions in our region occur through the original hospital, ${ }^{55}$ and we were able to also capture readmissions to other participating hospitals. Fourth, the severity of seasonal influenza varies each year and we included only data from 2019-2020. However, the mortality rate associated with hospital admissions with influenza in our study (6.1\%) is consistent with mortality rates of approximately $3 \%-6 \%$ in a systematic review involving more than 120000 hospital admissions with influenza, ${ }^{56}$ and our findings are similar to those of recent studies in France ${ }^{10}$ and the US. ${ }^{11}$ Fifth, increased use of dexamethasone and other COVID-19 treatments after our study period may affect estimates of mortality and accuracy of prediction scores. Validation in the latest treatment era would be valuable. Finally, we were unable to collect data regarding cause of death, which may be unreliable in administrative sources,${ }^{57}$ and therefore cannot report the number of patients who died directly because of COVID-19. The most responsible discharge diagnoses were attributed to COVID-19, viral pneumonia, sepsis or palliative care in $89.7 \%$ of patients who died with COVID-19, suggesting that most of these deaths are likely attributable to COVID-19.

\section{Conclusion}

Adults admitted to hospital with COVID-19 at 7 hospitals in Ontario during the first wave of the pandemic used substantial hospital resources and suffered high rates of mortality. These patients had significantly greater mortality, ICU use, invasive mechanical ventilation use and hospital length of stay than patients admitted with influenza. Mortality among patients admitted to hospital with COVID19 can be predicted with reasonable accuracy using simple scores.

\section{References}

1. Richardson S, Hirsch JS, Narasimhan M, et al. Presenting characteristics, comorbidities, and outcomes among 5700 patients hospitalized with COVID-19 in the New York City area [published erratum in JAMA 2020;323:2098]. JAMA 2020;323: 2052-9.

2. Goyal P, Choi JJ, Pinheiro LC, et al. Clinical characteristics of COVID-19 in New York City. N Engl J Med 2020;382:2372-4.

3. Chopra V, Flanders SA, O'Malley M, et al. Sixty-day outcomes among patients hospitalized with COVID-19. Ann Intern Med 2020 Nov. 11 [Epub ahead of print]. doi: $10.7326 /$ M20-5661.

4. Docherty AB, Harrison EM, Green CA, et al.; ISARIC4C investigators. Features of 20 133 UK patients in hospital with COVID-19 using the ISARIC WHO Clinical Characterisation Protocol: prospective observational cohort study. BMJ 2020;369:m1985.

5. Zhou F, Yu T, Du R, et al. Clinical course and risk factors for mortality of adult inpatients with COVID-19 in Wuhan, China: a retrospective cohort study [published erratum in Lancet 2020;395:1038]. Lancet 2020;395:1054-62.

6. Mitra AR, Fergusson NA, Lloyd-Smith E, et al. Baseline characteristics and outcomes of patients with COVID-19 admitted to intensive care units in Vancouver, Canada: a case series. CMAJ 2020;192:E694-701.

7. Cavayas YA, Noël A, Brunette V, et al. Early experience with critically ill patients with COVID-19 in Montreal. Can J Anaesth 2021;68:204-13.

8. Mortality analyses. Baltimore: Johns Hopkins University \& Medicine, Coronavirus Resource Centre. Available: https://coronavirus.jhu.edu/data/mortality (accessed 2020 Dec. 5).

9. Tolksdorf K, Buda S, Schuler E, et al. Influenza-associated pneumonia as reference to assess seriousness of coronavirus disease (COVID-19). Euro Surveill 2020; 25:2000258.

10. Piroth L, Cottenet J, Mariet A-S, et al. Comparison of the characteristics, morbidity, and mortality of COVID-19 and seasonal influenza: a nationwide, population-based retrospective cohort study. Lancet Respir Med 2020 Dec. 17 [Epub ahead of print]. doi: 10.1016/S2213-2600(20)30527-0.
11. Xie Y, Bowe B, Maddukuri G, et al. Comparative evaluation of clinical manifestations and risk of death in patients admitted to hospital with COVID-19 and seasonal influenza: cohort study. BMJ 2020;371:m4677.

12. Verma AA, Guo Y, Kwan JL, et al. Patient characteristics, resource use and outcomes associated with general internal medicine hospital care: the General Medicine Inpatient Initiative (GEMINI) retrospective cohort study. CMAJ Open 2017;5:E842-9.

13. Verma AA, Pasricha SV, Jung HY, et al. Assessing the quality of clinical and administrative data extracted from hospitals: the General Medicine Inpatient Initiative (GEMINI) experience. J Am Med Inform Assoc 2020 Nov. 4 [Epub ahead of print]. doi: 10.1093/jamia/ocaa225.

14. ICD-10-CA coding direction for suspected COVID-19 cases. Ottawa: Canadian Institute for Health Information; 2020. Available: www.cihi.ca/en/bulletin/icd-10 -ca-coding-direction-for-suspected-covid-19-cases (accessed 2020 Nov. 19).

15. Kadri SS, Gundrum J, Warner S, et al. Uptake and accuracy of the diagnosis code for COVID-19 among US hospitalizations. JAMA 2020;324:2553-4.

16. Hamilton MA, Calzavara A, Emerson SD, et al. Validating International Classification of Disease 10th Revision algorithms for identifying influenza and respiratory syncytial virus hospitalizations. PLoS One 2021;16:e0244746.

17. Hossein $\mathrm{H}$, Ali KM, Hosseini M, et al. Value of chest computed tomography scan in diagnosis of COVID-19; a systematic review and meta-analysis. Clin Transl Imaging 2020 Oct. 12 [Epub ahead of print]. doi: 10.1007/s40336-020-00387-9.

18. Mandell LA, Wunderink RG, Anzueto A, et al.; Infectious Diseases Society of America. American Thoracic Society. Infectious Diseases Society of America/ American Thoracic Society consensus guidelines on the management of community-acquired pneumonia in adults. Clin Infect Dis 2007;44:S27-72.

19. Metlay JP, Waterer GW, Long AC, et al. Diagnosis and treatment of adults with community-acquired pneumonia. An official clinical practice guideline of the American Thoracic Society and Infectious Diseases Society of America. Am J Respir Crit Care Med 2019;200:e45-67.

20. Dragan V, Wei Y, Elligsen M, et al. Prophylactic antimicrobial therapy for acute aspiration pneumonitis. Clin Infect Dis 2018;67:513-8.

21. RECOVERY Collaborative Group; Horby P, Lim WS, Emberson JR, et al. Dexamethasone in hospitalized patients with COVID-19: preliminary report. N Engl J Med 2020 July 17 [Epub ahead of print]. doi: 10.1056/NEJMoa2021436.

22. Godoy LC, Goligher EC, Lawler PR, et al. Anticipating and managing coagulopathy and thrombotic manifestations of severe COVID-19. CMAJ 2020;192:E1156-61.

23. Blum D, Meraz-Munoz A, Harel Z. Kidney injury associated with COVID-19. CMAJ 2020;192:E1065.

24. Tse F, Borgaonkar M, Leontiadis GI. COVID-19: advice from the Canadian Association of Gastroenterology for endoscopy facilities, as of March 16, 2020. J Can Assoc Gastroenterol 2020;3:147-9.

25. Wahidi MM, Shojaee S, Lamb CR, et al. The use of bronchoscopy during the coronavirus disease 2019 pandemic. Chest 2020;158:1268-81.

26. Healthcare Cost and Utilization Project (HCUP). Clinical Classifications Software Refined (CCSR). Rockville (MD): Agency for Healthcare Research and Quality; 2020. Available: www.hcup-us.ahrq.gov/toolssoftware/ccsr/ccs_ refined.jsp (accessed 2020 Dec. 10).

27. Verma AA, Guo Y, Kwan JL, et al. Prevalence and costs of discharge diagnoses in inpatient general internal medicine: a multi-center cross-sectional study. J Gen Intern Med 2018;33:1899-904.

28. Quan H, Li B, Couris CM, et al. Updating and validating the charlson comorbidity index and score for risk adjustment in hospital discharge abstracts using data from 6 countries. Am J Epidemiol 2011;173:676-82.

29. Postal Code Conversion File Plus (PCCF+). Ottawa: Statistics Canada. Available: www150.statcan.gc.ca/n1/en/catalogue/82F0086X (accessed 2021 Jan. 20).

30. Measuring health inequalities: a toolkit - area-level equity stratifiers using PCCF and PCCF+. Ottawa: Canadian Institute for Health Information; 2018. Available: www.cihi.ca/sites/default/files/document/cphi-toolkit-area-level-measurement -pccf-2018-en-web.pdf (accessed 2021 Jan. 20).

31. Fortis S, O'Shea AMJ, Beck BF, et al. An automated computerized critical illness severity scoring system derived from APACHE III: modified APACHE. J Crit Care 2018;48:237-42.

32. Fortis S, O'Shea AMJ, Beck MAEBF, et al. A simplified critical illness severity scoring system (CISSS): development and internal validation. J Crit Care 2021; 61:21-8.

33. Lu J, Hu S, Fan R, et al. ACP risk grade: a simple mortality index for patients with confirmed or suspected severe acute respiratory syndrome coronavirus 2 disease (COVID-19) during the early stage of outbreak in Wuhan, China. medRxiv 2020 Feb. 23. doi: 10.1101/2020.02.20.20025510.

34. Hu C, Liu Z, Jiang Y, et al. Early prediction of mortality risk among patients with severe COVID-19, using machine learning. Int J Epidemiol 2021;49:1918-29.

35. Xie J, Hungerford D, Chen $\mathrm{H}$, et al. Development and external validation of a prognostic multivariable model on admission for hospitalized patients with COVID-19. medRxiv 2020 Apr. 7. doi: 10.1101/2020.03.28.20045997. 
36. National Early Warning Score (NEWS) 2. London (UK): Royal College of Physicians. Available: www.rcplondon.ac.uk/projects/outputs/national-early-warning -score-news-2 (accessed 2021 Jan. 20).

37. Gupta RK, Marks M, Samuels THA, et al.; UCLH COVID-19 Reporting Group. Systematic evaluation and external validation of 22 prognostic models among hospitalised adults with COVID-19: an observational cohort study. Eur Respir J 2020;56:2003498.

38. Wynants L, Van Calster B, Collins GS, et al. Prediction models for diagnosis and prognosis of COVID-19 infection: systematic review and critical appraisal [published erratum in BMJ 2020;369:m2204]. BMJ 2020;369:m1328.

39. Knight SR, Ho A, Pius R, et al.; ISARIC4C investigators. Risk stratification of patients admitted to hospital with covid-19 using the ISARIC WHO Clinical Characterisation Protocol: development and validation of the 4C Mortality Score [published erratum in BMJ 2020;371:m4334]. BMJ 2020;370:m3339.

40. Austin PC. Using the standardized difference to compare the prevalence of a binary variable between two groups in observational research. Commun Stat Simul Comput 2009;38:1228-34.

41. Clift AK, Coupland CAC, Keogh $\mathrm{RH}$, et al. Living risk prediction algorithm (QCOVID) for risk of hospital admission and mortality from coronavirus 19 in adults: national derivation and validation cohort study. BMJ 2020;371:m3731.

42. Tai DBG, Shah A, Doubeni CA, et al. The disproportionate impact of COVID-19 on racial and ethnic minorities in the United States. Clin Infect Dis 2020 June 20 [Epub ahead of print]. doi: 10.1093/cid/ciaa815.

43. Liu M, Maxwell $\mathrm{CJ}$, Armstrong P, et al. COVID-19 in long-term care homes in Ontario and British Columbia. CMAJ 2020;192:E1540-6.

44. Zou G. A modified poisson regression approach to prospective studies with binary data. Am J Epidemio/ 2004;159:702-6.

45. Ontario Agency for Health Protection and Promotion (Public Health Ontario). Daily epidemiologic summary: COVID-19 in Ontario - January 15, 2020 to June 30, 2020. Toronto: Queen's Printer for Ontario; 2020. Available: https://files. ontario.ca/moh-covid-19-report-en-2020-07-01.pdf (accessed 2021 Jan. 20).

46. Brazeau NF, Verity R, Jenks S, et al. Report 34: COVID-19 infection fatality ratio estimates from seroprevalence. London (UK): MRC Centre for Global Infectious Disease Analysis, School of Public Health, Imperial College London; 2020:1-18.
Available: www.imperial.ac.uk/mrc-global-infectious-disease-analysis/covid-19 /report-34-ifr/ (accessed 2021 Jan. 28).

47. Pastor-Barriuso R, Pérez-Gómez B, Hernán MA, et al. Infection fatality risk for SARS-CoV-2 in community dwelling population of Spain: nationwide seroepidemiological study. BMJ 2020;371:m4509.

48. Ioannidis JPA, Axfors C, Contopoulos-loannidis DG. Population-level COVID-19 mortality risk for non-elderly individuals overall and for non-elderly individuals without underlying diseases in pandemic epicenters. Environ Res 2020;188:109890.

49. Wu C, Chen X, Cai Y, et al. Risk factors associated with acute respiratory distress syndrome and death in patients with coronavirus disease 2019 pneumonia in Wuhan, China. JAMA Intern Med 2020;180:934-43.

50. Lavery AM, Preston LE, Ko JY, et al. Characteristics of hospitalized COVID-19 patients discharged and experiencing same-hospital readmission: United States, March-August 2020. MMWR Morb Mortal Wkly Rep 2020;69:1695-9.

51. Takahashi T, Ellingson MK, Wong $P$, et al. Sex differences in immune responses that underlie COVID-19 disease outcomes. Nature 2020;588:315-20.

52. Fisman DN, Bogoch I, Lapointe-Shaw L, et al. Risk factors associated with mortality among residents with coronavirus disease 2019 (COVID-19) in long-term care facilities in Ontario, Canada. JAMA Netw Open 2020;3:e2015957.

53. Niedzwiedz CL, O'Donnell CA, Jani BD, et al. Ethnic and socioeconomic differences in SARS-CoV-2 infection: prospective cohort study using UK Biobank. BMC Med 2020;18:160.

54. Sloan C, Chandrasekhar R, Mitchel E, et al. Socioeconomic disparities and influenza hospitalizations, Tennessee, USA. Emerg Infect Dis 2015;21:1602-10.

55. Staples JA, Thiruchelvam D, Redelmeier DA. Site of hospital readmission and mortality: a population-based retrospective cohort study. CMAJ Open 2014;2:E77-85.

56. Pormohammad A, Ghorbani S, Khatami A, et al. Comparison of influenza type A and B with COVID-19: a global systematic review and meta-analysis on clinical, laboratory and radiographic findings. Rev Med Virol 2020 Oct. 9 [Epub ahead of print]. doi: 10.1002/rmv.2179.

57. Mikkelsen L, Iburg KM, Adair T, et al. Assessing the quality of cause of death data in six high-income countries: Australia, Canada, Denmark, Germany, Japan and Switzerland. Int J Public Health 2020;65:17-28.
Competing interests: Amol Verma and Fahad Razak report personal fees from Ontario Health. Michael Fralick reports personal fees from Pine Trees, outside the submitted work. No other competing interests were declared.

This article has been peer reviewed.

Affiliations: Li Ka Shing Knowledge Institute (Verma, Hora, Jung, Chan, Mamdani, Razak), St. Michael's Hospital, Unity Health Toronto; Department of Medicine (Verma, Fralick, Malecki, Lapointe-Shaw, Weinerman, Tang, Kwan, Liu, Rawal, Cheung, Herridge, Mamdani, Razak), and Institute of Health Policy, Management and Evaluation (Verma, Cheung, Mamdani, Razak), University of Toronto, Toronto, Ont.; Department of Geography and Environmental Management (Hora), University of Waterloo, Waterloo, Ont.; Department of Medicine (Fralick, Kwan), Sinai Health System; Department of Medicine (Lapointe-Shaw, Liu, Rawal, Cheung, Herridge) and Toronto General Hospital Research Institute (Lapointe-Shaw), University Health Network; Women's Institute for Health System Solutions and Virtual Care (Lapointe-Shaw), Women's College Hospital; ICES Central (Lapointe-Shaw, Rosella); Department of Medicine (Weinerman), Sunnybrook Health Sciences Centre; Institute for Better Health (Tang, Rosella), Trillium Health Partners, Mississauga, Ont.; Department of Mechanical and Industrial Engineering (Chan), University of Toronto; Joint Department of Medical Imaging (Cheung), University Health Network; Division of Epidemiology (Cheung, Rosella), Dalla Lana School of Public Health; Vector Institute (Rosella, Ghassemi); Department of Computer Science (Ghassemi) and Leslie Dan Faculty of Pharmacy (Mamdani), University of Toronto, Ont.

Contributors: The study was conceived by all authors and designed by Amol Verma and Fahad Razak, with substantial input from all authors. Amol Verma, Tejasvi Hora, Hae Young Jung, Michael Fralick, Sarah Malecki, Lauren Lapointe-Shaw, Adina Weinerman, Terence Tang, Janice Kwan, Jessica Liu, Shail Rawal and Fahad Razak contributed to data collection. Tejasvi Hora and Hae Young Jung conducted the data analysis. All authors contributed interpretation of results. Amol Verma wrote the first draft of the manuscript. All authors provided critical revisions for important intellectual content, gave final approval of the version to be published and agreed to be accountable for all aspects of the work.

Content licence: This is an Open Access article distributed in accordance with the terms of the Creative Commons Attribution (CC BY-NC-ND 4.0) licence, which permits use, distribution and reproduction in any medium, provided that the original publication is properly cited, the use is noncommercial (i.e., research or educational use), and no modifications or adaptations are made. See: https://creativecommons.org/licenses/by-nc-nd/4.0/

Funding: This project was supported by CIHR Grant VR4-172743. The development of the GEMINI data platform has been supported with funding from the Canadian Cancer Society, the Canadian Frailty Network, the Canadian Institutes of Health Research, the Canadian Medical Protective Association, Green Shield Canada Foundation, the Natural Sciences and Engineering Research Council of Canada, Ontario Health, the St. Michael's Hospital Association Innovation Fund, and the University of Toronto Department of Medicine, with in-kind support from partner hospitals and Vector Institute. Funders had no role in the design, conduct or interpretation of this study.

Data sharing: Data from this manuscript can be accessed upon request to the corresponding author, to the extent that is possible in compliance with local research ethics board requirements and data sharing agreements.

Acknowledgements: The authors thank Dr. Radha Koppula for performing manual chart abstraction, and Mr. Daniel Tamming and Mr. Sudipta Saha for contributing to data analysis. The authors also acknowledge the people and organizations that have made the data available for this research.

Accepted: Jan. 28, 2021

Correspondence to: Amol Verma, amol.verma@mail.utoronto.ca 